\title{
CUIDADO À MULHER EM SITUAÇÃO DE VIOLÊNCIA DOMÉSTICA NO ÂMBITO DA ESTRATÉGIA SAÚDE DA FAMÍLIA
}

\section{CARE FOR WOMEN IN THE SITUATION OF DOMESTIC VIOLENCE IN THE FRAMEWORK OF THE FAMILY HEALTH STRATEGY}

\author{
Giberto Alves Dias', Jeniffer Souza Silva', Luanna Rodrigues de Jesus' ${ }^{2}$, Ninalva de Andrade \\ Santos', Vanda Palmarella Rodrigues ${ }^{1}$
}

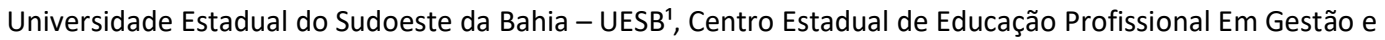
Tecnologia da Informação Regis Pacheco - CEEP²

\begin{abstract}
The purpose of this study was to describe the care of women in situations of domestic violence developed by professionals who work in the Family Health Strategy. Descriptive, qualitative research, which had as participants 24 professionals from the Family Health Units of a municipality in the interior of Bahia. The data were collected through semi-structured interviews and analyzed by the thematic content analysis technique. The results showed that the professionals guide women about the different forms of violence and others do not consider domestic violence as a public health problem, neglecting the care actions of women in situations of domestic violence. Emphasis is also placed on technical care and the lack of training courses on violence. There is a need for professional training that equips health teams to re-signify practices of caring for women in situations of violence, including prevention, identification and referral to network services.
\end{abstract}

Keywords: Domestic violence; Violence against women; Women's Health; Gender Relationships; Family Health Strategy.

\section{Resumo}

Objetivou-se descrever o cuidado à mulher em situação de violência doméstica desenvolvido por profissionais que atuam na Estratégia Saúde da Família. Pesquisa descritiva, qualitativa, que teve como participantes 24 profissionais das Unidades de Saúde da Família de um município do interior baiano. Os dados foram coletados por meio de entrevistas semiestruturada e analisados pela técnica de análise de conteúdo temática. Os resultados mostraram que as(os) profissionais orientam as mulheres sobre as diferentes formas de violência e outras(os) não consideram a violência doméstica como um problema de saúde pública, negligenciando as ações de cuidado às mulheres em situação de violência doméstica. Destaca-se ainda a ênfase nos cuidados técnicos e a carência de cursos de capacitação sobre violência. Urge a necessidade de uma formação profissional que instrumentalize as equipes de saúde a ressignificarem as práticas de cuidado à mulher em situação de violência contemplando a prevenção, identificação e encaminhamento aos serviços da rede.

Palavras chave: Violência Doméstica; Violência contra a mulher; Saúde da Mulher; Relações de Gênero; Estratégia Saúde da Família. 
Introdução

Denomina-se violência doméstica e familiar contra a mulher toda ação ou omissão baseada no gênero que possa causar morte, lesão, sofrimento físico, sexual ou psicológico, além de dano moral ou patrimonial. Pode se consolidar de diversas formas, a exemplo da violência física (compreende lesões e danos à integridade física das mulheres); a violência psicológica (abrange rebaixamentos, retraimento, repulsas e ameaças); a violência patrimonial (concretizada em roubo, retenção ou danos aos bens materiais, recursos e/ou documentos); a violência verbal (caracterizada por xingamentos, ofensas, ameaças e injúrias); e a violência sexual (presente nas relações sexuais forçadas ou práticas sexuais não consentidas) ${ }^{1-2}$.

A violência doméstica contra a mulher guarda intrínseca relação com fatores biológicos, econômicos, culturais, políticos, sociais e, sobretudo, com as desigualdades de poder entre homens e mulheres configuradas nas relações de gênero que podem culminar no feminicídio. A Lei 13.104 de 2015 determina o feminicídio como a modalidade de homicídio qualificado incluído no rol dos crimes hediondos, que ocorre quando uma mulher vem a ser vítima de homicídio simplesmente por razões de ser mulher. ${ }^{3}$

Dados epidemiológicos desnudam a magnitude da problemática que se apresenta em caráter ascendente ao longo do tempo. O Mapa da Violência 2015, por meio dos registros do Sistema de Informação sobre Mortalidade (SIM), aponta um aumento de $252 \%$ entre 1980 e 2013 , 106.093 mulheres foram vítimas de homicídio ${ }^{4}$.

Soma-se a estes, dados oriundos do Ligue 180 (Central de Atendimento à Mulher), que no primeiro semestre do ano de 2015 registrou 179 casos de agressão contra a mulher, por dia, sendo 92 relacionados à violência física, 55 à violência psicológica e sete à violência sexual ${ }^{5}$. Todavia, considerando-se a subnotificação, já que muitos desses casos, apesar de serem atendidos nos serviços de saúde permanecem sem identificação da causa básica que motivou a procura pela unidade, pode-se inferir que essa problemática na realidade é maior do que revelam os dados oficiais.

A taxa de 4,8 homicídios por 100 mil mulheres, coloca o Brasil num grupo de 83 países com dados homogêneos, fornecidos pela Organização Mundial da Saúde, ocupando a 5ạ posição, evidenciando que estes índices excedem em muito, os encontrados na maior parte dos países do mundo ${ }^{4}$.

Ademais, acrescenta-se aos fatores de vulnerabilidade para a violência doméstica contra a mulher a cor da pele. Com poucas exceções geográficas, a população negra é a mais vitimizada por homicídio no país. O número de homicídios de mulheres brancas passou de 1.747, em 2003, para 1.576, em 2013 (queda de 9,8\% no total de homicídios do período). Porém, os homicídios de mulheres negras aumentaram $54,2 \%$ no mesmo período, passando de 1.864 para 2.875 vítimas ${ }^{4}$.

A distribuição destes casos acontece de forma divergente no território brasileiro. Entre 2003 a 2013, diversos estados apresentaram crescimento da violência doméstica contra a mulher, como Roraima (343,9\%) e a Paraíba $(229,2 \%)$. Em contrapartida, sete Unidades da Federação (UF) registraram quedas leves ou significativas: Mato Grosso do Sul $(-0,1 \%)$, Amapá $(-5,3 \%)$, Rondônia $(-11,9 \%)$, Pernambuco $(-15,6 \%)$ e Mato Grosso (-16,6\%); São Paulo e no Rio de Janeiro (acima de 30\%). Por outro lado, contrariando as expectativas, após a vigência da Lei 11.340/2006, conhecida como Lei Maria da Penha $^{1}$, apenas cinco UF registraram quedas nas taxas de violência doméstica contra a mulher: Rondônia, Espírito Santo, Pernambuco, São Paulo e Rio de Janeiro ${ }^{4}$.

Esta realidade evidencia a probabilidade de as(os) profissionais de saúde cuidarem de mulheres que sofreram agressões física e/ou de outras formas. Neste sentido, a falta de capacitação acerca das condutas que devem ser tomadas, pode inviabilizar a tomada de decisão essencial à integralidade da assistência ${ }^{6}$. Há de se considerar ainda o silêncio da mulher em situação de violência doméstica por temer novas represálias por parte do parceiro enfurecido pela denúncia.

Ademais, problemas econômicos, preocupação com as crianças, dependência emocional, falta de apoio da família e de amigos e a esperança de que o parceiro irá mudar, direcionam as mulheres à permanência nas relações violentas. Esse é o retrato de uma realidade multifacetada pelos estereótipos de gênero e pelos determinantes socioeconômicos que interferem no processo saúde-doença da coletividade em geral ${ }^{7}$.

Nessa perspectiva, este estudo teve como questão de pesquisa: Quais os cuidados desenvolvidos pelas equipes da Estratégia Saúde da Família (ESF) à mulher em situação de violência doméstica?

Pesquisas que têm como objeto de estudo à violência doméstica são relevantes para a compreensão da complexidade desse fenômeno. Evidenciar as estatísticas e as lacunas existentes 
no combate da mesma é estratégia importante para a prevenção e controle do agravo. Para tanto, conhecer como se efetiva a práxis de cuidado no âmbito da ESF, porta de entrada das mulheres em situação de violência no âmbito do Sistema Único de Saúde (SUS) pode se apresentar como importante indicador da realidade.

Dessa forma, tendo em vista os fatos supracitados, esse trabalho teve como objetivo descrever o cuidado à mulher em situação de violência doméstica desenvolvido por profissionais que atuam na Estratégia Saúde da Família.

\section{Metodologia}

Pesquisa descritiva, de natureza qualitativa, realizada com 24 profissionais de saúde (quatro enfermeiras(os), três técnicas(os) de enfermagem, uma(um) auxiliar de enfermagem, 13 agentes comunitários de Saúde (ACS), uma(um) cirurgião-dentista e duas(dois) técnicas(os) de saúde bucal (TSB)) que atuam em Unidades de Saúde da Família (USF) da zona urbana, de um município do interior baiano.

O estudo constitui recorte do projeto de pesquisa intitulado "Violência doméstica contra a mulher: representações sociais das equipes de saúde da família", o qual contemplou os requisitos éticos exigidos pela Resolução 466 de 2012. O projeto de pesquisa foi submetido ao Comitê de Ética em Pesquisa da Universidade Estadual do Sudoeste da Bahia/Campus de Jequié sob CAAE: 49736915.3.0000.0055 e aprovado sob parecer $\mathrm{n}$ 0 1.304.618/2015.

Para a seleção das USF foram utilizados como critérios de inclusão: Unidade onde funcionam duas equipes ou equipe única da ESF, localizada na zona urbana e com equipe mínima completa, conforme os critérios preconizados pelo Ministério da Saúde. Cinco USF que atenderam aos critérios de inclusão foram selecionadas (uma equipe única e quatro duplas), mediante a disponibilidade das(os) profissionais de saúde. Foram excluídas as USF que apresentavam mais de duas equipes atuando na mesma estrutura física ou que estivessem em reforma.

Para a escolha das(os) participantes, utilizou-se como critério de inclusão: profissional de saúde da equipe da ESF com atuação mínima de seis meses de experiência na USF. E como critério de exclusão o afastamento do serviço por férias ou licença de qualquer natureza.

Após contato com a coordenação da USF, foi solicitado agendamento para um encontro com as(os) profissionais das equipes da ESF.
Às(Aos) profissionais de saúde foi apresentada à pesquisa, e aos(às) que aceitaram participar, apresentava-se o Termo de Consentimento Livre e Esclarecido (TCLE).

Os dados foram coletados no período de agosto de 2016 a abril de 2017, por meio de entrevista guiada por roteiro semiestruturado. As entrevistas foram aplicadas em local privativo da USF, de forma individualizada, com o auxílio de gravador, com duração média de 40 minutos. 0 roteiro continha pontos para caracterização sociodemográfica das(os) participantes e as questões disparadoras relacionadas à percepção das práticas de cuidado desenvolvidas à mulher em situação de violência pela equipe da ESF e ações desenvolvidas para o enfrentamento da violência doméstica contra a mulher.

Para análise de dados, procedeu-se à aplicação da Técnica de Análise de Conteúdo, modalidade temática. Nessa perspectiva, inicialmente foi realizada a transcrição detalhada das entrevistas, buscando-se registrar sem nenhuma sintetização ou correção às falas das(os) profissionais de saúde. Em seguida, passou-se às fases de pré-análise, exploração do material, tratamento dos dados, inferência e interpretação ${ }^{8}$.

A partir dos resultados emergiram as seguintes categorias: 1) Orientação e diálogo como práticas de cuidado desenvolvidas à mulher em situação de violência doméstica pela equipe da ESF e 2) Lacunas na Formação/capacitação profissional para atuar nos casos de violência doméstica contra a mulher.

Para garantir o anonimato, utilizou-se a letra $E$, de entrevistada(o), seguida de um algarismo arábico correspondente à ordem crescente de realização da entrevista.

\section{Resultados e discussão}

Participaram da pesquisa 24 profissionais $(91,6 \%$ do sexo feminino e $8,3 \%$ do sexo masculino), com faixa etária entre 25 a 61 anos, sendo $50 \%$ casadas(os), $8,3 \%$ em união consensual, $25 \%$ solteiras(os) e $16,6 \%$ divorciadas(os). Em relação à escolaridade, 37,5\% tem ensino médio completo, $25 \%$ cursaram ensino superior completo e $12,5 \%$ cursaram o ensino superior incompleto. Apenas $25 \%$ cursaram pós-graduação em nível Lato sensu, sendo que $50 \%$ informaram que participaram de atualização sobre violência doméstica contra a mulher.

Categoria 1: Orientação e diálogo como práticas de cuidado desenvolvidas à mulher em situação de 


\section{violência doméstica pela equipe da ESF}

Nesta categoria, as(os) profissionais de saúde fizeram referências à orientação e ao diálogo como práticas de cuidado à mulher em situação de violência doméstica no âmbito da ESF. Por outro lado, alguns discorreram sobre a inexistência de ações frente a esta problemática.

Orientações às vítimas, frente aos casos que envolvem violência doméstica contra a mulher foi uma forma de cuidado evidenciada pelas(os) profissionais de saúde.

A gente fala: ele tá estuprando você, porque o sexo, só é sexo quando ele é em comum acordo, quando ele deixa de ser comum acordo, ele já não é um sexo saudável [...] (E2, ACS).

A gente dá assim, orientações [...] fala com elas durante a consulta mesmo [...] os tipos de violência, pois elas não sabem, às vezes elas sofrem, mas pensam que não é violência, geralmente [...] (E20, Enfermeira).

A situação de violência que não envolve agressão física pode não ser reconhecida pela vítima, sendo esta falta de percepção um agravante para a naturalização do evento e, consequentemente para a tolerância da violência que tem como agressor na maioria das vezes o parceiro ${ }^{9}$.

Os achados deste estudo mostraram que as(os) profissionais das equipes da ESF são capazes de identificar mulheres em diferentes situações de violência doméstica. Todavia, essas mulheres não reconhecem tais situações como formas de violência. Nessa perspectiva, entendese que, esse fato possa ser decorrente do sistema patriarcal predominante, o qual caracteriza a submissão do sexo feminino frente ao masculino.

Dessa forma, a orientação do(a)s profissionais de saúde reflete uma modalidade de cuidado relevante para à mulher em situação de violência, a qual pode ser considerada uma iniciativa para o enfrentamento da violência e das formas de submissão que cercam as relações de poder estabelecidas entre o homem e a mulher.

O não reconhecimento das situações de violência por parte das mulheres, foi encontrado em outros estudos a exemplo do realizado no município de Vitória da Conquista-BA no qual, para as(os) autoras(es), evidenciam que a percepção das(os) profissionais relacionam as agressões negligenciadas à naturalização das mulheres nessa situação sobre as ocorrências.
Frente a esta faceta perversa, nota-se que as situações de violência não são percebidas pelas mulheres. As agressões são incorporadas tão fortemente no cotidiano e na cultura de uma localidade, que se torna naturalizada, dificultando por vezes que a mulher em situação de violência doméstica, os familiares, a própria sociedade e, também, profissionais de saúde a reconheçam como violência doméstica ${ }^{10}$.

Em relação à violência sexual, referida pela(o) entrevistada(o) 2, destaca-se um estudo realizado na região noroeste do Rio Grande do Sul, que reafirmou as raízes do patriarcado para a submissão da mulher evidenciando a construção social e cultural da prática sexual como uma das obrigações do casamento/relação estável "impondo" a mulher a satisfação dos desejos do companheiro. Nessa ótica, as aspirações da mulher são sucumbidas, sendo a obrigatoriedade da prática sexual percebida como uma forma de violência. Contudo, apesar deste reconhecimento, as mulheres permanecem aceitando esta situação por temor de sofrerem agressões maiores $^{11}$.

Neste sentido, orientar pode ser uma das estratégias usadas para empoderar à mulher em situação de violência doméstica. Em algumas pesquisas a orientação ocorria, principalmente, no sentido de esclarecer e encaminhar. Em geral, as(os) entrevistadas(os) iniciavam o encaminhamento da situação à enfermeira coordenadora da ESF ou Unidade Básica de Saúde, sendo determinadas quais ações seriam adotadas. As orientações visavam o empoderamento das mulheres no intuito de desnaturalizarem a violência presente em suas vidas $^{12}$

O diálogo, como uma forma de cuidado à mulher em situação de violência doméstica, pode representar apoio para a mulher ou ser agente motivador de riscos para as(os) profissionais de saúde.

A não ser mesmo pela questão da conversa, do diálogo, ela vem pra as consultas e conversa com a enfermeira, a gente conversa nas visitas domiciliar, tentando de alguma forma que ela se abra pra isso, e também que ela tome alguma atitude $[. .$.$] (E23, ACS).$

Teve uma enfermeira aqui que foi se intrometer, foi conversar com a moça, a moça chegou em casa e foi falar com o marido que era traficante, que a enfermeira falou, isso, isso e isso dele, aí o traficante veio aqui tirar pergunta da enfermeira, aí diante disso a gente tem medo de se 
envolver $[\ldots](E 6, T S B)$.

O diálogo aprofunda-se nas dimensões subjetivas imbricadas na violência, sendo essas dimensões experimentadas e compreendidas a partir dos modos singulares nos quais cada pessoa percebe a realidade e interage com ela ${ }^{13}$.

Nota-se, ser o diálogo agente fortalecedor do vínculo entre as(os) profissionais da ESF e a clientela que está sob seu cuidado, instrumento que pode nortear a tomada de decisão por parte da mulher violentada, como por exemplo, a denúncia.

Em relação à atuação das(os) ACS, estudo realizado em 2014 evidencia que essas(es) profissionais têm maiores chances de identificar a violência doméstica, por serem as(os) principais responsáveis pelas visitas domiciliares ${ }^{14}$. Dessa forma, entende-se ser a(o) ACS, desde que capacitado, um aliado para a notificação, a orientação, o encaminhamento, a denúncia e o empoderamento da mulher. Todavia, por serem residentes na microárea e, provavelmente terem contato próximo ao agressor, tornam-se necessárias ações e políticas públicas que garantam sua segurança.

Neste sentido, algumas pesquisas evidenciam o medo de envolvimento nos casos de violência por parte das(os) profissionais de saúde. No que se refere aos vários impedimentos e as dificuldades compreendidas, o temor e a insegurança foram os que mais apareceram nas narrativas, pois as(os) profissionais de saúde se sentem desprotegidas(os) e em situação de risco ao se depararem com ações de cuidado a outrem que guarda relação com casos de violência. $O$ medo de presumíveis retaliações e advertências de agressores influencia no desempenho da(o) profissional que, na maioria das vezes, não contempla a grandeza social da problemática, limitando-se a atuar na esfera tecnicista simplesmente ${ }^{10}$.

Diferente disso, um estudo realizado no Chile, na região de La Araucaína, elaborou um modelo multidisciplinar de pesquisa-ação em territórios com situações de violência à mulher. $\mathrm{O}$ estudo buscou fortalecer os laços comunitários, tendo como um dos pontos de partida o diálogo entre as pessoas dos territórios, ampliando informações as quais ajudassem a projetar um modelo de intervenção que se adaptasse às características locais ${ }^{15}$.

O diálogo se iniciou com diferentes autoridades da região como: pastores evangélicos, profissionais de saúde, maxi (xamã na cultura mapuche), diretor regional do Serviço Nacional de Mulheres, professoras(es) e outros, o que garantiu o desenho de uma abordagem baseada no diálogo entre autoridades, mulheres em situação de violência doméstica e agressores a fim de ajudar no combate à violência contra a mulher ${ }^{15}$.

Dessa forma, nota-se o diálogo como um cuidado de relevância à mulher em situação de violência, sendo que, por meio de estratégias como as supracitadas no estudo chileno, é possível estabelecer o diálogo entre os envolvidos no contexto da violência e garantir a segurança das(os) profissionais de saúde e demais profissionais que integram a rede de atenção à mulher em situação de violência doméstica.

Especificamente no setor saúde, as instituições envolvidas na atenção às pessoas em situação de violência devem assegurar cada etapa do atendimento que for necessária. Isso inclui medidas de prevenção, emergência, acompanhamento, reabilitação e tratamento de eventuais impactos resultantes da violência sobre a saúde física e psicológica, além do abortamento legal caso seja solicitado pela mulher, em casos de estupro ${ }^{16}$.

Em oposição, algumas falas elucidadas pelas(os) profissionais de saúde demonstraram a inexistência de ações mediante as situações de violência doméstica contra a mulher.

[...] na verdade, tenho muita dificuldade, até de explicar, porque quando você encontra uma equipe que conversa e que tenta resolver [... ], mas nem sempre a gente dá a sorte de encontrar [...] (E4, ACS).

[...] Eu nunca acionei aqui, a gente aciona a Secretaria, tem situações que a gente aciona o Conselho, mas essas questões de envolver a Delegacia da Mulher essas coisas não, porque a gente como profissional não tem como [...] tem que ser a própria [...] (E5, Enfermeira).

Não, definitivamente não existe [...] mas também a gente não quer muito tomar a frente (E7, ACS).

Cuidar da mulher em situação de violência doméstica requer, dentre outras coisas, na percepção das(os) entrevistadas(os), que haja um bom processo de comunicação entre os membros da equipe que atuam na ESF.

Por outro lado, algumas(alguns) profissionais ainda não encaram a violência doméstica contra a mulher como um problema de saúde pública. Dessa forma, busca-se até mesmo responsabilizar a mulher como única pessoa capaz de solucionar a situação.

Para a(o) entrevistada(o) 6, poucas(os) 
profissionais se comprometem a ajudar as mulheres em situação de violência doméstica. Nesse sentido, subentende-se que cuidar, na perspectiva da integralidade, parece não fazer parte da atenção a essas mulheres. Umas das fragilidades da ESF se caracteriza por profissionais que não notificam, não orientam, não dialogam, não empoderam e muitas vezes não veem a violência como uma problemática de saúde pública ${ }^{9}$, como se percebe na fala da(o) entrevistada(o).

Um estudo realizado em Minas Gerais, com 12 mulheres em situação de violência doméstica perpetrada por parceiro íntimo corroborou com muitos dos achados desta pesquisa ao destacar o despreparo das(os) profissionais do serviço e a falta de humanização no atendimento, quando não resolutivos, com interações que não encorajavam a confiança e não protegiam as mulheres, o que propiciava a exposição e maior fragilização destas ${ }^{17}$.

O Protocolo da Atenção Básica: Saúde das Mulheres, preconizado pelo Ministério da Saúde em 2016, aborda os procedimentos a serem seguidos em casos de atenção à mulher em situação de violência sexual e/ou doméstica/intrafamiliar. Segundo o documento, é direito da mulher o acolhimento com escuta qualificada, a avaliação global por equipe multidisciplinar, o exame físico geral e/ou específico, a dispensação e administração de medicamentos para profilaxias indicadas (em caso de violência sexual), feito por enfermeira(o) ou médica(o), o estabelecimento de plano de segurança para mulheres com risco de vida por equipe multidisciplinar, entre outros direitos ${ }^{16}$. Esse protocolo não foi referido pelas(os) participantes deste estudo.

Divergindo dos achados desta pesquisa, estudo realizado em Portugal avaliou 39 estruturas designadas como casas de abrigo às mulheres em situação de violência doméstica, as quais obtiveram bons resultados em relação aos cuidados oferecidos. Verificou-se que os abrigos oferecem acolhimento, boa estrutura, segurança, cuidados emocionais às vítimas, apoio à autonomia e restabelecimento de projetos de vida ${ }^{18}$.

Ressalta-se ainda que a notificação dos casos de violência doméstica contra a mulher constitui estratégia importante para o dimensionamento de sua ocorrência, bem como, para a tomada de decisão de ações que busquem sua prevenção e controle. Assim, é imprescindível que as(os) profissionais de saúde estejam aptos a identificar e a notificar o acontecimento.
Frente às várias e complexas facetas da violência como fenômeno social e suas diversas extensões, as(os) profissionais de saúde se percebem ineficazes para enfrentarem a problemática ao tempo em que evidenciam ser o cuidado focado na perspectiva clínico-biologicista, de caráter fragmentado e restritivo, insuficiente para a esperada tomada de decisão no campo da integralidade. Estas evidências apontam para o despreparo e déficit de conhecimento que permita evidenciar as questões sociais e psicológicas necessárias ao desempenho que os casos de violência requerem ${ }^{10}$.

Categoria 2: Lacunas na formação/capacitação profissional para atuar nos casos de violência doméstica contra a mulher

$\mathrm{Na}$ segunda categoria, as(os) participantes destacaram as fragilidades na formação e o desconhecimento de outros serviços de apoio à mulher em situação de violência doméstica.

As falas dos(as) profissionais de saúde evidenciaram o despreparo na formação profissional para atuarem nessa realidade.

[...] Eu não estava preparada [...] na Faculdade não ensina [...] é uma área delicada, é uma área que eu tenho muito pouco conhecimento [...] (E14, Enfermeira).

[...] Se tem capacitação pra outras coisas, deveria ter pra isso também que é recorrente. Muitos casos a gente percebe, $e$ os que a gente não percebe? [...] (E13, TSB).

Os relatos das(os) participantes afirmam que tanto problemas de formação quanto à falta de capacitação no decorrer da atuação profissional, são barreiras para a resolução dos casos de violência. Impulsionada pela força do modelo médico hegemônico, de atenção centrado na doença, a formação acadêmica tem se mostrado frágil no reconhecimento de determinados agravos à saúde da população brasileira, tais como a violência doméstica contra a mulher ${ }^{19}$.

O despreparo das(os) profissionais das equipes da ESF resulta em atuação limitada. Este enfoque impede a práxis de um cuidado centrado no princípio da integralidade e da intersetorialidade, limitando a ação cuidadora a uma questão clínica, restringindo o caráter social.

Em outra pesquisa, as(os) participantes se reconheceram sem preparo considerando os percalços limitantes durante a graduação, dado ser a formação focada no paradigma médico hegemônico e pelo déficit de ações de educação 
permanente em saúde no cotidiano da atuação nas unidades de saúde. O não saber agir frente aos casos de violência doméstica acaba suscitando a atuação com base na improvisação, nas experiências do dia a dia e na capacidade de sensibilidade de cada ser, fato que prejudica a qualidade do cuidado realizado ${ }^{9}$.

No entanto, a problemática de formação/capacitação das(os) profissionais de saúde ante à violência doméstica contra a mulher não é um problema recorrente apenas no Brasil. Um estudo realizado no Hospital Clínico Universitário Virgen de la Arrixaca de Murcia na Espanha, evidenciou que atualmente a violência de gênero continua a ser um grave problema social e de saúde pública. Muitos casos são apresentados às(aos) profissionais de saúde, mas poucos são detectados precocemente. Portanto, a formação é um eixo fundamental no qual, um nível adequado de conscientização é alcançado para detectar mulheres vítimas de abuso e fazer uma abordagem correta do problema ${ }^{20}$.

Além disso, o estudo corrobora com os resultados desta pesquisa ao afirmar que, as(os) profissionais de saúde encontram obstáculos para lidarem com as mulheres em situação de violência. A maioria das(os) profissionais argumentam que a formação escassa sobre o assunto e a ignorância do protocolo de ação são as principais barreiras. Assim, o estudo conclui que atitudes mais motivadoras e preocupadas devem ser adotadas em treinamento adequado sobre o assunto ${ }^{20}$.

Como elucidado nas falas do presente estudo, o despreparo no decorrer da formação acadêmica impulsiona cada vez mais o número de profissionais despreparadas(os) no mercado de trabalho para lidarem com a violência doméstica contra a mulher.

Nessa perspectiva, é necessário questionar se os modelos de formação em saúde frequentemente baseados em uma concepção pedagógica vertical e hierarquizada têm colaborado para as mudanças necessárias, no sentido de se fortalecer e articular essas(es) profissionais-cidadãs(os) na luta para transformar os determinantes sociais da saúde ${ }^{21}$.

As(Os) profissionais das equipes da ESF ressaltaram ainda que desconhecem os serviços que integram a rede de atenção à mulher em situação de violência doméstica.

[...] só conheço mesmo a Delegacia da Mulher [...] e não tenho acesso a outros tipos de tratamentos que tenham pra essas mulheres, eu não conheço, desconheço mesmo [...] (E11, Dentista).
[...] também porque a unidade não desenvolve nada sobre esse assunto e aí o que eu conheço mesmo é a Delegacia da Mulher $[. .].(E 10, A C S)$.

Os serviços de saúde devem atuar de forma mais eficiente na detecção de situações de violência e serem mais ativos na articulação com os demais setores, por serem equipamentos importantes da rede institucionalizada e uma das principais portas de entrada de mulheres em situação de violência doméstica ${ }^{17}$. Todavia, como uma das principais fragilidades encontradas na assistência dos serviços, as(os) entrevistadas(os) mencionaram a desarticulação entre os serviços da rede.

Os relatos das(os) profissionais evidenciam a dificuldade de encaminhar as mulheres em situação de violência doméstica aos serviços de apoio. Além disso, nota-se o desconhecimento sobre os serviços que formam a rede intersetorial de atenção à mulher nessa situação. Ainda, percebe-se que além da inexistência de articulação, não há o reconhecimento da violência como um problema de saúde pública, uma vez que o assunto não é abordado nas ESF.

A mesma situação foi notada em um estudo ao destacar que a intervenção nesses casos é multiprofissional, interdisciplinar e interinstitucional. As equipes da ESF devem agregar as organizações e serviços disponíveis na comunidade às intervenções de prevenção e combate à violência doméstica, a exemplo das Delegacias da Mulher, dos serviços de assistência social, do Conselho Tutelar, Ministério Público e instituições como casas-abrigo, grupos de mulheres e creches, entre outros ${ }^{22}$.

Nesse sentido, com base nas falas das(os) profissionais de saúde, urge a necessidade de maior aprimoramento nas práticas de cuidados à mulher em situação de violência doméstica, no intuito de viabilizar a articulação com os demais serviços que integram a rede de atenção visando a apoiar a mulher no enfrentamento da violência doméstica.

Outro estudo mostrou que, de 221 profissionais de saúde, 202 (90\%) referiram ter atendido mulheres em situação de violência e todas(os) relataram algum tipo de conduta ou encaminhamento. Dessas(es) 202 profissionais, 99 (49\%) referiram ter realizado uma consulta clínica e algum encaminhamento para outro serviço e/ou profissional, 80 (39,6\%) referiram apenas a realização da consulta clínica e 23 $(11,4 \%)$ afirmaram apenas ter encaminhado as mulheres, sem a realização de nenhum tipo de consulta clínica, médica ou de enfermagem. 
Entretanto, a articulação intersetorial ainda se demonstrou pequena ${ }^{23}$.

A falta de articulação entre os serviços é outro aspecto destacado pelos estudos, mostrando que a mulher muitas vezes não conhece os serviços que integram a rede de atenção responsável para seu atendimento, seja no âmbito jurídico, social ou ainda nos setores de saúde. A esta lacuna, evidencia-se a importância de fortalecimento da rede de atenção à mulher em situação de violência para o enfrentamento desta problemática possibilitando a articulação intersetorial ${ }^{24}$.

Assim, ao comparar os estudos supracitados e as falas elucidadas, percebe-se a necessidade de qualificação sobre a rede intersetorial. Nesse sentido, ressalta-se a urgência de capacitações às(aos) profissionais das equipes da ESF e demais profissionais da rede, para que, dessa forma, haja a articulação entre os diferentes serviços que integram a referida rede estabelecendo efetiva comunicação entre estes, pois a perspectiva da intersetorialidade depende de um trabalho que funcione de forma multiprofissional/interdisciplinar e não isolada.

\section{Conclusões}

Os resultados deste estudo apontam lacunas na formação profissional em relação à identificação e manejo dos casos de violência doméstica contra a mulher, limitando suas ações ao diálogo e orientações. Em algumas situações evidencia-se a invisibilidade da violência e a falta de conhecimento dos serviços que integram a rede de atenção à mulher em situação de violência doméstica.

Ressalta-se ser necessária a realização de capacitações para as(os) profissionais das equipes da ESF relacionados com as questões de gênero e violência doméstica contra a mulher, de modo que estejam preparadas(os) à prestação de cuidados na perspectiva da integralidade, permeados pela escuta ativa como uma das estratégias de acolhimento.

Além disso, urge a necessidade de preparar estas(es) profissionais de saúde para que sejam capazes de identificar as várias formas de violência doméstica contra a mulher, que conheçam a rede de apoio para que o sistema de referência e contrarreferência seja efetivo. Ademais, que estejam sensibilizadas(os) para a importância da notificação dos casos identificados.

Por sua vez, frente à complexidade das ações que permeiam os casos de violência doméstica contra a mulher reitera-se a importância da estruturação da rede intersetorial com a finalidade de proporcionar maior resolutividade aos casos. Esta articulação se mostra indispensável para que as(os) profissionais das equipes da ESF se sintam protegidos ao realizarem as notificações da violência contra a mulher por ser esta ação uma obrigatoriedade da(o) profissional de saúde.

\section{Referências}

1. Brasil. Secretaria de Políticas para as Mulheres. Lei Maria da Penha: Lei 11.340 de 7 de agosto de 2006 - Coíbe a violência doméstica e intrafamiliar contra a mulher. Brasília, DF: Presidência da República; 2011.

2. Signorelli MC, Auad D, Pereira PPG. Violência doméstica contra mulheres e a atuação profissional na atenção primária à saúde: um estudo etnográfico em Matinhos, Paraná, Brasil. Saúde Debate. 2014; 38(102):482-93.

3. Brasil. Lei n. 13.104, de 9 de março de 2015. Altera o art. 121 do Decreto-Lei no 2.848, de 7 de dezembro de 1940 - Código Penal, para prever o feminicídio como circunstância qualificadora do crime de homicídio, e o art. 1으 da Lei no 8.072, de 25 de julho de 1990, para incluir o feminicídio no rol dos crimes hediondos. Diário Oficial da República Federativa do Brasil, 10 Mar 2015. Seção 1.

4. Waiselfisz JJ. Mapa da Violência 2015. Atualização: Homicídios de Mulheres no Brasil. Flacso Brasil; 2015.

5. Central de Atendimento à Mulher [homepage na Internet]. 179 relatos por dia de violência contra mulheres por dia em 2015: o balanço do ligue 180 [atualizada em 2017 Dec 23; acesso em 2018 Mar 9]. Disponível em: http://www.brasil.gov.br/cidadania-e-

justica/2015/10/179-relatos-de-violencia-contramulheres-por-dia-em-2015-o-balanco-do-ligue$\underline{180}$

6. Santos J, Andrade LR, Reis AL, Duarte, PFS. Conhecimento de enfermeiras em unidades de saúde sobre a assistência à mulher vítima da violência. Revista Baiana de Enfermagem, Salvador. 2014; 28(3):260-70.

7. Piosiadlo LCM, Fonseca RMGS, Gessner R. Subalternidade de gênero: refletindo sobre a vulnerabilidade para violência doméstica contra a mulher. Esc Anna Nery, Rio de Janeiro. 2014; 18(4): 728-33.

8. Bardin L. Análise de conteúdo. São Paulo: Edições 70; 2011.

9. Netto LA, Moura MAV, Silva GF, Penna LHG, Pereira, ALFP. Mulheres em situação de 
violência pelo parceiro íntimo: tomada de decisão por apoio institucional especializado. Rev Gaúcha Enferm. 2015; 36(esp):135-42. doméstica e sexual no âmbito da Estratégia de Saúde da Família: atuação profissional e barreiras para o enfrentamento. Physis. 2014; 24(3): 787807.

11. Silva EB, Padoin SMM, Vianna LAC. Mulher em situação de violência: limites da assistência. Ciênc Saúde Colet. 2015; 20(1): 24957.

12. Arboit J, Padoin SMM, Vieira LB, Paula CC, Costa MC, Cortes LF. Atenção à saúde de mulheres em situação de violência dos profissionais em rede. Rev Esc Enferm USP. 2017; 51:e0320.

13. Mandelbaum B, Schraiber LB, d'Oliveira AFPL. Violência e vida familiar: abordagens psicanalíticas e de gênero. Saúde Soc. 2016; 25(2): 422-30.

14. Moreira TNF, Martins CL, Feuerwker LCM, Schraiber LB. A construção do cuidado: o atendimento às situações de violência doméstica por equipes de Saúde da Família. Saúde Soc. 2014; 23(3): 814-21.

15. Romero LMK, Muñoz CM, Henríquez MC Higueras AS, Ancalaf AT, Nitrihual, et al. Modelo participativo para el abordaje de la violencia contra las mujeres en La Araucanía, Chile. Rev Panam Salud Publica. 2017; 41(8):1-4.

16. Ministério da saúde (BR). Protocolos da Atenção Básica: Saúde das Mulheres. Brasília, DF: Ministério da Saúde, Instituto Sírio-Libanês de Ensino e Pesquisa; 2016.

17. Santos WJ, Freitas MIF. Fragilidades e Potencialidades da Rede de Atendimento às Mulheres em Situação de Violência por Parceiro Íntimo. Rev Min Enferm. 2017; 21:e-1048.

18. Correia AL, Sani Al. As casas de abrigo em Portugal: Caracterização estrutural e funcional destas respostas sociais. Análise Psicológica. 2015; 33(1): 89-96.

19. Cordeiro KCC, Santos RM, Gomes NP, Melo DS, Mota RS, Couto TM. Formação profissional e notificação da violência contra a mulher. Revista Baiana de Enfermagem. 2015; (29)3: 209-17.

20. Alcaraz $\mathrm{CL}$, Roche $\mathrm{FP}$, Hernández $\mathrm{MT}$, Meseguer CB, Rodriguez JDP, Esparza AO. Formación y detección de La violência de gênero em La profesión sanitaria. Rev Enferm UFSM. 2014; 4(1): 217-26.

21. Berger SMD, Barbosa RHS, Soares CT, Bezerra CM. Formação de Agentes Comunitárias de Saúde para o enfrentamento da violência de gênero: contribuições da Educação Popular e da

pedagogia feminista. Interface. 2014; 18(supl.1): 1241-54

22. Machado JC, Rodrigues VP, Vilela ABA, Simões AV, Morais RLGL, Rocha EN. Violência intrafamiliar e as estratégias de atuação da equipe de Saúde da Família. Saúde Soc. 2014; 23(3): 828-40.

23. Hasse $M$, Vieira EM. Como os profissionais de saúde atendem mulheres em situação de violência? Uma análise triangulada de dados. Saúde Debate. 2014; (38)102: 482-93.

24. Rodrigues VP, Oliveira GP, Machado JC, Simões AV, Pires VMMM, Morais RLGL. Assistência à saúde da mulher em situação de violência doméstica: revisão integrativa. Revista Saúde.Com. 2018; 14(1): 1121-29.

\section{Endereço para Correspondência}

Universidade Estadual do Sudeste da Bahia UESB

Rua, Av. José Moreira Sobrinho, s/n - Jequiezinho, Jequié - BA

CEP.:45206-190

e-mail: gondim.vilara@gmail.com

Recebido em 01/03/2018

Aprovado em 29/08/2018

Publicado em 20/12/2018 